\title{
The Inheritance and Development of Chinese Folk Custom Culture - Example by Linyi
}

\author{
Li Zhu \\ Feixian College, Linyi University, Feixian ,Shandong, China \\ zhulifx_2012@163.com
}

Keywords: Folk custom culture; Inheritance; Development; Linyi

\begin{abstract}
With the quickening industrialization and urbanization processes and the development of modern media, the soil on which the Chinese folk custom culture depends for existence and development collapses gradually, and new challenges are faced by the inheritance and development of Chinese folk custom culture. The extinction tendency is gradually presented in the folk custom culture; Pursue for economic benefit in an one-sided way and develop the folk custom culture excessively; The folk custom culture has no successor; People's entertainment activities in information age are increased, the development vitality of folk custom culture is lost. Only by emphasizing the problems existing in the current folk custom culture inheritance and responding actively with corresponding countermeasures, can the Chinese traditional culture be inherited and developed.
\end{abstract}

\section{Introduction}

With a long history and numerous nationalities, China has accumulated rich folk custom culture resources, not only rich in contents but also varied in forms. The folk custom culture not only involves literature, artistry, music, diet, dancing and many other forms, but also includes martial system, religion, ethnic medicine, festival activities and many other resources.

The well-known folk culture expert Professor Zhong Fulan points out in Introduction of the Study of Chinese Folk Custom Culture that, "folk custom refers to the daily customs of the public and it is an important social culture phenomenon" [1]. As a kind of culture, folk custom has its own rules in appearance, evolvement and development. Any one folk custom is not born without reason, but is closely related to the natural environment, social environment and people's production and living ways. It is a kind of cultural phenomenon created by the public in their social life practice and then inherited constantly. It can be said that the folk custom culture is an important constituent part of Chinese traditional culture [2].

\section{Introduction of Linyi Folk Custom Culture}

Located in the southeast of Shandong Province, China, Linyi has a history of over 2500 years as it is established in the year of BC492. In the long process of history, Linyin forms its own unique customs and habits, which are very rich no matter in the contents or varieties of the folk custom culture. Linyi folk custom culture includes many categories such as folk music, folk opera, folk dancing, folk handicraft, folk diet and folk literature, etc. Among them, Yimeng Mountain in Minor was rated by the UNESCO as the excellent folk song in China, renowned at home and abroad; the Five Major Tunes in South Shandong Province was listed by the State Council in the second batch of State-level Non-material Cultural Heritage in 2008; "dragon dancing and pavilion carrying" is a famous item of folk custom culture in Sanguanmiao Community, Hedong District of Linyi and it was listed in the third batch of State-level Non-material Cultural Heritage by the State Council in 2010; Yimeng printed calico, Xiaoguo clay figurine, Yimeng paper-cut, Gaoqiao hand embroidering and Chuzhuang clay sculpture are all the well-known folk handicrafts of Linyi; the famous folk diet includes Yimeng pancake, eight-treasure fermented soya beans, rice grain and Lanling wine, etc. With the passage of time and the transition of ages, the vitality presented in the folk custom culture of Linyi 
constantly reduces and even some folk customs are on the verge of disappearance. Currently, the youth in Linyi has no idea of the folk customs in Linyi at all and they even do not know what the Five Major Tunes in south Shandong Province are. Many folk customs of Linyi have fallen in to the situation of no successors.

\section{Challenges Faced in the Inheritance and Development of Linyi Folk Custom Culture}

Along with the quickening industrialization and urbanization as well as the development of modern media, the soil on which the folk custom culture depends for existence and development collapses gradually, many cultural relics and historical sites, ancient architectures, folk literatures and arts suffered great damage, various folk custom culture activities are gradually losing, the traditional opera, technical skills and music are facing the situation of extinction, folk artisans face "faultage"; plus the excessive development and unreasonable use of folk custom culture in many places, the extinction of folk custom culture is quickened.

The Economic Globalization Brings Impact to the Inheritance and Development of Linyi. folk custom culture. Although the advent of economic globalization drives the development of cultural diversification, it also brings some negative influences so that some local cultures in the inferior position are also faced by the verge of extinction. In case of such cultural impact, the cultural integration and collision make people have great changes in entertainment forms and contents under the background of cultural diversity, while the folk custom culture is hard to adapt to the spiritual and cultural demands of the young generation. Many people, especially the youth, no longer focus on the excellent traditional culture of China, but show much concern on the foreign cultures such as "foreign festivals" and "western fast-food", etc., so the extinction tendency is gradually presented in the folk custom culture.

Pursue for Economic Benefit in an One-sided Way and Develop the Folk Custom Culture. excessively Since the reform and opening up, governments at all levels begin to emphasize economic benefit but ignore the sustainable utilization of folk custom culture in the development of folk custom culture, they even "kill the goose that lays the golden eggs" and makes excessive development of folk custom culture. Some places take the development of scenic spots with featured cultural resources as the "magic weapon" of their local economic development; along with the increase of people's income and the change of their consumption idea, they have increasingly more consumption demands for cultural and spiritual products. The "holiday tourism" becomes more and more popular, and especially the cultural tourism involving historical and cultural scenic spots are favored by the common public. The huge amount of customers causes severe damage to the local folk custom heritages. Some local governments spend a lot of money to pull down many houses and blindly build various infrastructures, but they ignore the protection to the folk custom culture. The wide roads, tidy city appearance, and comfortable hotels promote the development of tourism in local place and attract many tourists, but the construction of roads damages the original taste and flavor of the folk custom heritages; the abundant hotels and restaurants are in disharmony with the overall impression of the folk custom heritages; furthermore, some local governments even make up some nonexistent folk customs to cheat the tourists to attract the tourists and satisfy their psychology of seeking for novelty, so that the folk custom culture suffers commercialization and vulgarization. Such phenomenon of emphasizing economic value but ignoring the cultural value in the folk custom culture makes many excellent folk custom cultures destroyed, distorted or run into extinction [3].

The Self Deficiencies of Folk Custom Culture cannot Adapt to the Development of the New Times. The folk custom culture of Linyi is the achievement of Linyi people after the long-term accumulation, long-term innovation and long-term inheritance in the social practice. Also, with the passage of time and the advance of the age, its contents and forms both develop constantly. However, some contents and forms not able to adapt to the age are also developing, for example, some old folk customs such as superstition and vulgar contents also exist. Such vulgar culture will definitely not promote the cultural construction in Linyi. At the same time, the inheritance forms of master 
instructing apprentice and oral teaching and the communication way of folk spreading impede the inheritance and development of Linyi folk custom culture [4].

The Folk Custom Culture has no Successor. In the agricultural age, due to the extremely deficient material goods, the successors of folk custom culture take their artistries as the ability to set foot in the society and feed his family. Their artistries cannot be spread to those not in their families and should be absolutely confidential. Therefore, according to the old maxim, the inheritance subjects always follow the sermon of "inherit to male but not female successors, and inherit to family members". The communication way of folk custom arts is mainly through oral teaching that inspires true understanding within. However, currently, the successors of many Chinese folk culture heritages are in "old age", they generally enter into the aging and declining peak period, and even some national treasure level folk custom culture heritages face the phenomenon of "no successor", so that the folk custom culture has a relatively narrow inheritance range and its successors are few. Plus the development of modern science and technology and the change of people's aesthetic taste, as well as the great abundance of industrial products and electronic products, many people especially the young people do not have the previous enthusiasm for traditional skills and art any more. Many folk custom products have no market, and the income from the work of folk artistry is low, unable to maintain the living of the artists, so that there is no successor for the folk artistries. For example, three of the four successors of the "Xiaoguo clay figurine" of Cangshan county have been over the age of 80 years old, and the fourth successor Liu Fuxiang is also approaching 70 years old; there is not any young successor except of them. For another example, the current quantity of permanent staff in Liuqin Opera Troupe of Linyi is only 32, and the young people are not willing to join in the troupe due to the lack of salary guarantee. [5]

People's Entertainment Activities in Information Age are Uncreased, the Development Vitality of Folk Custom Culture is Lost. China's folk custom culture is mainly generated under the background of ancient small-scale production when people have a low living rhythm. In agricultural era, the villagers depend on agricultural activities for living; they begin their work at sunrise and come back home at sundown, living a relatively simple and tedium life. In the temple fairs, various delicate handcrafts and excellent folk songs and dances inject some colors to the simple life of villagers. People seek for entertainment through viewing the various folk custom art activities, which also promote the affective communications among them. After the urbanization, informationization and modern media invade people's daily life deeply, people have increasingly diversified entertainment ways; as their pace of life is quickened, people have no much leisure time for the appreciation of kinds of folk custom arts and especially the audiences for folk operas are fewer and fewer, so the development vitality of folk custom culture is lost.

\section{Countermeasures for the Inheritance and Development of Chinese Folk Custom Culture}

Depend on Government's Strength. The government plays a leading role in the protection of folk custom culture. Except of the great support in folk custom culture from financial power and material power, the government also plays a major role in successor training, legal protection and management, etc [6]. The attitude and management of the government to folk customs, its policies, actions and propaganda, etc. always have deep influence on the inheritance of folk customs. The collection, organization and publishing of folk custom arts need fund, so do the creation and performance of folk custom culture products. Therefore, the government shall offer support economically. For the regions with advantages in folk custom resources, the government should give great support in such policies as fiscal subsidies, taxes and license granting. The protection of folk custom culture also needs to fully mobilize the strengths of experts and scholars, news media, business circles, the common public and all sectors of the society under the leading of the government. [7]

Education is the Important Means to Inherit Folk Custom Culture. Only when the new generation of China really undertakes the role of successor and bears the responsibilities of successor, 
can the Chinese folk custom culture be inherited. Currently, not only the children but also some young students have no idea of the Chinese traditional culture. Education is an important means to inherit folk custom culture and only education can play the long-term effective function to the protection and inheritance of Chinese folk custom culture. The school is not only the battle field for publicizing folk custom culture and studying folk custom culture, but also the place to cultivate talents of folk custom culture. No matter primary and secondary school students or college students, they should all accept the education about folk custom culture. After they learn much about Chinese traditional culture, their interest in studying and inheriting folk custom culture can be aroused. Also the school can open up speeches about special festivals and propagate the cultural knowledge about traditional festivals. [8]

Strengthen the Propaganda of Folk Custom Culture. The inheritance and development of folk custom culture needs to take the overall cultural environment in the society as the important support, so as to attract more people to pay attention to and focus on the folk custom culture. With the strengthening propaganda of folk custom culture, people can experience, feel and understand the unique charming and connotations of folk custom culture personally. On one hand, the folk custom activities can be held in all places to extend the influence of folk custom culture; on the other hand, the propaganda for the status of folk custom culture needs to be increased, so that people can realize the dangerous situation of folk customs and generate the motives to inherit the folk custom culture in Linyi. Along with the development of technology, the propaganda role of network, radio, TV and other media shall be fully exerted, the protection awareness shall be cultivated, and the protection knowledge shall be popularized, so as to form good atmosphere of protecting folk custom culture in the whole society and promote the propagation of folk custom culture [9].

Emphasize the Cultivation of Folk Custom Culture Talents. Talent is the important foundation for realizing the inheritance of Linyi folk custom culture and promoting its development, so it is of great practical significance to establish reasonable talent cultivation and training system in the inheritance and development of Linyi folk custom culture. In the cultivation of Linyi folk custom culture talents, necessary support and protection shall be given to the current folk culture artists through increasing the salary and welfare. On the other hand, the training and education to folk custom culture successors shall be emphasized. Also the condition that most folk custom culture successors are relatively old and low in education degree shall also be brought to the forefront, so active measures shall be adopted for their cultivation again, so as to improve the quality of Linyi folk custom culture inheritance, and extend the innovation space for Linyi folk custom culture. In addition, the emphasis for the cultivation of Linyi folk custom culture successors shall be placed in the younger generation [10].

\section{Conclusions}

Folk custom culture is the mirror of a nationality or an area. It can reflect the traditional and real features of the nationality or the area. It is not only ancient but also young; it is traditional but also modern. Linyi folk custom culture must be effectively inherited and developed, which requires the current society to objectively face the problems in the inheritance and development of Linyi folk custom culture and make persistent efforts through the exploration of the development rules of Linyi custom culture as well as the inheritance and development strategies.

\section{Acknowledgements}

This research was financially supported by Teaching Reform Project of Linyi University (2014067) and the National Research Bureau of cultural relics, cultural heritage protection areas of science and technology (2013-YB-SQ-222). 


\section{References}

[1] F.L. Zhong, Introduction of the Study of Chinese Folk Custom Culture, Shanghai Lexicographical Publishing House, Shanghai, 2007. (In Chinese)

[2] J.W. Zhong, Outline and Emergence of Folklore Culture, Zhonghua Book Company, Beijing, 1996. (In Chinese)

[3] Y.P. Song, Development and Protection of Folklore Cultural Resources, Large Stage. 6(2013) 230-231. (In Chinese)

[4] L.Y. Fan, The Inheritance and Development of Hebei Folk Custom Culture, Large Stage. 4 (2013) 248-249. (In Chinese)

[5] W. Shuai, Q. Qian, Inheritance of Chinese Folklore Culture and Governmental Support, National Art Research. 4(2013) 12-18. (In Chinese)

[6] L. Dong, Domestic Trouble and Foreign Invasion of Intangible Cultural Heritage Protection: Unclear Inheritance Mechanism, Legal Daily, http://ip.people.com.cn/GB/139288/12037653.html. (In Chinese)

[7] F. Liao, Study of the Government Responsibilities in the Inheritance and Development of Folk Custom Culture in China, ( MS., Hunan Normal University, China 2012), p.18-19. (In Chinese)

[8] M.G. Liu, Study of the Inheritance, Protection and Utilization of Intangible Cultural Heritage in Folklore, Jianghan Tribune. 10 (2012) 119-125. (In Chinese)

[9] G.L. Xu, Transition of Current Inheritance Approaches of Folk Customs and Relevant Problems, Folklore Studies. 3(2015) 29-38. (In Chinese)

[10] Y.J. Bai, Significance and Countermeasures of China's Folklore Culture Development in the New Trend, College Journal of Shanxi Normal University (Social Science Edition). S1 (2012) 119-121. (In Chinese) 